\title{
Remnants fragments preserve genetic diversity of the old forest lichen Lobaria pulmonaria in a fragmented Mediterranean mountain forest
}

\author{
Mónica G. Otálora • Isabel Martínez • Rocío Belinchón • \\ Ivo Widmer • Gregorio Aragón • Adrián Escudero • \\ Christoph Scheidegger
}

Received: 6 October 2010/Accepted: 14 February 2011/Published online: 26 February 2011

(C) Springer Science+Business Media B.V. 2011

\begin{abstract}
Fragmentation represents a serious threat to biodiversity worldwide, however its effects on epiphytic organisms is still poorly understood. We study the effect of habitat fragmentation on the genetic population structure and diversity of the red-listed epiphytic lichen, Lobaria pulmonaria, in a Mediterranean forest landscape. We tested the relative importance of forest patch quality, matrix surrounding fragments and connectivity on the genetic variation within populations and the differentiation among them. A total of 855 thalli were sampled in 44 plots $\left(400 \mathrm{~m}^{2}\right)$ of 31 suitable forest fragments (beeches and oaks), in the Sierra de Ayllón in central Spain. Variables related to landscape attributes of the remnant forest patches such as size and connectivity and also the nature of the matrix or tree species had no significant effects on the genetic diversity of L. pulmonaria. Values of genetic diversity (Nei's) were only affected by habitat quality estimated as the age patches. Most of the variation (76\%) in all populations was observed at the smallest sampled unit (plots). Using multiple regression analysis, we found that habitat quality is more important in explaining the genetic structure of the L. pulmonaria populations than spatial distance. The relatively high level of genetic diversity of the species in old forest patches regardless of patch size indicates that habitat quality in a highly structured forest stand determines the population size and distribution pattern of this species and its associated lichen community. Thus, conservation programmes of Mediterranean mountain forests have to prioritize area and habitat quality of old forest patches.
\end{abstract}

Keywords Lichens · Habitat fragmentation - Landscape genetics · Microsatellites · Mediterranean forest

M. G. Otálora $(\varangle)$ · I. Martínez · R. Belinchón · G. Aragón · A. Escudero Área de Biodiversidad y Conservación, ESCET, Universidad Rey Juan Carlos, C/Tulipán s/n, 28933 Mostoles, Spain e-mail: monica.garcia@urjc.es

M. G. Otálora · I. Widmer · C. Scheidegger

WSL, Swiss Federal Institute for Forest, Snow and Landscape Research, Zürcherstrasse. 111, 8903 Birmensdorf, Switzerland 


\section{Introduction}

Anthropogenic impacts to ecosystems result in changes in the distribution and abundance of species, particularly in areas affected by habitat destruction (Johansson and Ehrlén 2003; Ries et al. 2004). Fragmentation represents a threat to biodiversity worldwide by reducing the amount of suitable habitat, increasing isolation between habitat patches, and changing biotic and abiotic conditions within remnants (Fahrig 2003). Population genetics theory predicts that habitat fragmentation can disrupt breeding systems, resulting in increased inbreeding and erosion of genetic diversity within populations, together with a substantial population differentiation (Young et al. 1996; Hamrick 2004). In addition, a population subject to habitat fragmentation faces increasing isolation of the resulting subpopulations, leading to two major genetic effects: genetic drift leading to increasing differentiation among subpopulations and declining genetic diversity within subpopulations (Templeton et al. 1990).

It is also well known that some species are at greater risk of extinction in fragmented landscapes than others (Hoehn et al. 2007). Identifying the factors that make these species so sensitive to fragmentation and understanding how fragmented habitat may affect population viability are essentials for conservation management of fragmented populations. Only with this information available can integrative ecological and evolutionary principles of species at risk be implemented in conservation planning. For instance, the current paradigm in plant population genetics has not been tested in other groups of organisms. Cryptogamic epiphytes, associated to old forests, are especially sensitive to habitat quality, which may be affected by fragmentation. Consequently many epiphyte species have experienced sharp population declines parallel to the conversion of continuous forests into small fragments of sheltered landscape (Sjöberg and Ericson 1992; Snäll et al. 2004; Löbel et al. 2006; Scheidegger and Werth 2009). However, the effects of habitat fragmentation on the genetic structure and diversity of epiphytic organisms have been largely neglected and the genetic consequences on these organisms remain poorly understood (Lättman et al. 2009).

How landscape fragmentation affects individual organisms is dependent on the attributes of the organisms (Henle et al. 2004; Schmuki et al. 2006) and their interaction with the biotic and abiotic changes produced after the fragmentation. Therefore, the combination of molecular genetics tools with landscape ecological concepts, more specifically landscape genetics (Manel et al. 2003), can aid in understanding the processes driving genetic diversity, structure and population persistence (Holderegger and Wagner 2008). Patch size and isolation are the predictors often used to describe fragmented landscapes and to investigate the effects of habitat fragmentation on community and species dynamics (Hanski and Gaggiotti 2004). More recently using landscape genetic approaches, the relevance of habitat quality, landscape history and also the nature of the matrix surrounding each remnant have taken in account when studying the genetic effects of fragmentation on species (Nielsen et al. 2006; Williams et al. 2006; Werth et al. 2007; Holderegger and Wagner 2008).

A consensus exists in which the effect of fragmentation is dependent on the ability of species to disperse and colonize such habitats at different scales (Hanski and Gaggiotti 2004; Münzbergová and Herben 2005; Pohjamo et al. 2008; Löbel et al. 2009). Genetic markers provide a powerful tool for obtaining indirect estimates of dispersal and gene flow in natural populations by evaluating the genetic structure and diversity of species at nested spatial and temporal scales. The genetic structure and diversity of lichen-forming fungi has been the subject recently of many studies, reporting mixed conclusions regarding dispersal abilities, habitat characteristics and landscape levels (Lättman et al. 2009). 
Our main goal is to evaluate the effect of habitat fragmentation on the genetic structure and diversity of the epiphytic lichen, Lobaria pulmonaria, in a Mediterranean forest landscape. L. pulmonaria is one the most studied lichen species. It is mainly an epiphytic lichen of humid temperate and boreal regions of the northern hemisphere and cooler parts of the tropics occupying also well conserved stands in the Mediterranean region (Belinchón 2009; Belinchón et al. 2009). Lobaria pulmonaria produces both vegetative and sexual propagules and it has been historically considered a dispersal-limited species. However, recent studies suggest that in many parts of the species' distribution area the most important factor for the population persistence of this species is the establishment stage and recruitment rather than dispersal (Werth et al. 2006a; Belinchón 2009; Scheidegger and Werth 2009).

In Mediterranean fragmented mountain forest, habitat quality (i.e. tree species and forest stand age) profoundly affects the occurrence and cover of Lobaria pulmonaria, at several spatial scales from the tree to the patch level (Belinchón et al. 2009). Therefore, we hypothesized that genetic differentiation between habitat types and qualities would result from genetic drift during dispersal, recruitment or growth in relation to spatial isolation of forest patches in a fragmented forest landscape. To test our hypothesis we compared the local genetic diversity and structure of this species in forest patches with the characteristics of the patches (including host tree species, patch size, connectivity and surrounding matrix) and a complete set of environmental predictors taken at different scales in the forest fragments. This study applies landscape genetic methods with a multimodel approach that evaluates alternative hypotheses and identifies a combination of environmental factors that appear to drive gene flow in this fragmented Mediterranean landscape. We identified which factors are affecting the genetic diversity and structure of this model lichen species and discuss implications for the conservation of this species.

\section{Materials and methods}

\section{Sampling}

The study area is a mosaic of beech (Fagus sylvatica) and Mediterranean oak (Quercus pyrenaica) forest remnants embedded in a matrix dominated by heathlands (Erica arborea and E. australis) and pine afforestations (Pinus sylvestris). It covers 5600 ha and is located in the Sierra de Ayllón, at the eastern most tip of the Sistema Central Range, Spain $\left(41^{\circ} 13^{\prime} \mathrm{N} 3^{\circ} 21^{\prime} \mathrm{W}\right)$. The climate is Mediterranean with a mean annual temperature of $7.8^{\circ} \mathrm{C}$ $\left(0.10^{\circ} \mathrm{C}\right.$ January $-19.2^{\circ} \mathrm{C}$ July) and an annual rainfall of $1039 \mathrm{~mm}$ (1408-1835 m a.s.l.). Loss and forest fragmentation have occurred extensively, although some well-preserved beech forests restricted to areas of difficult access remain. From the 1960s to date, most forests have been clear-cut and modern forestry practices have maintained a Pinus sylvestris afforestations and extense Erica communities (Hernández and Sainz 1978). The studied area included both north and south facing slopes of the Ayllón Mountains. The southern slopes are currently under protection within the Natural Park "Hayedo de Tejera Negra" whereas the northern slope (Riaza) is not formally protected. The south facing slopes include two valleys, both with different topographic and landscape characteristics: Zarzas River and Lillas River. The management and intensity of fragmentation has also varied in these three regions. The forest patches matrix of Riaza is dominated by heathlands, and in Lillas and Zarzas the matrixes are a mixture among pine afforestation and heathlands. For more details about the study area and landscape characteristics see 
Belinchón et al. (2009). A hierarchical sampling design was implemented, Riaza, Lillas and Zarzas were considered regions, each region comprise several forest patches of beeches and oaks, and each forest patches may include several plots of $400 \mathrm{~m}^{2}$. A total of 44 plots in 31 forest patches along the three regions were sampled. The forest patches area ranged from 0.75 to 209.80 ha and the distance between patches ranged from $200 \mathrm{~m}$ to $8 \mathrm{~km}$, with a mean distance of $3.10 \mathrm{~km}(\mathrm{SD}=1.63)$ (Belinchón et al. 2009).

Aerial photographs 1:1000 were taken from SigPac (http://sigpac.jccm.es/visorSigpac/) and analyzed to identify forest patches, which were delimited and drawn in a GIS. From the 55 plots of $20 \times 20 \mathrm{~m}^{2}$ randomly sampled by Belinchón et al. (2009), the 44 plots with Lobaria pulmonaria were selected for this study (34 plots were in beech patches and 10 plots were in oak patches). Variables describing forest patch characteristics: area (ha), connectivity, and percentaje of matrix pine perimeter were estimated using GIS (ArcView GIS 3.1) as described by Belinchón et al. (2009). Within each plot we sampled 20 lichen thalli each from a different tree. Multiple thalli from the same tree were sampled in plots with fewer than 20 trees occupied by L. pulmonaria. In seven plots less than 20-thalli were collected (see Table 1). Thus, we sampled a total of 855 thalli of $L$. pulmonaria. Each plot was georeferenced. At the plot level we measured the total number of trees per plot, trees carrying L. pulmonaria per plot, diameter at breast height $(\mathrm{dbh}, \mathrm{cm})$, tree species (oak or beech) and plot distance to the nearest permanent water course (m, using GIS) (Table 1). Lichen species cover below 2-m height was measured in square centimetres (L. pulmonaria rarely grows above this height in the study area). Because the surrounding matrix may influence the persistence and dispersal of L. pulmonaria (Belinchón et al. 2009), the perimeter pine afforestations bordering each patch was also recorded as a surrogate of the complex nature of the matrix (Table 2).

Genetic analyses

Lobaria pulmonaria samples from fresh material were ground in liquid nitrogen. Total genomic DNA was extracted using the DNeasy Plant Mini Kit (Qiagen) according to the manufacturer's instructions with slight modifications described in Crespo et al. (2001). Three unlinked fungal microsatellites LPu03, LPu09 and LPu15 were analyzed (Walser et al. 2003, 2004). The loci were amplified in a multiplex PCR of $10 \mu \mathrm{l}$ using $1 \mu \mathrm{l}$ of genomic DNA, $2 \mu \mathrm{l}$ of the Qiagen Multiplex PCR Master Mix solution and $25 \mathrm{nM}$ of the primers LPu03, LPu09 and LPu15. DNA amplifications were carried out in a Peltier thermal cyclers (PTC-100) and performed using the following programs: initial denaturation at $95^{\circ} \mathrm{C}$ for $15 \mathrm{~min}$, and 27 cycles $94^{\circ} \mathrm{C}$ for $45 \mathrm{~s}, 55^{\circ} \mathrm{C}$ for $90 \mathrm{~s}, 72^{\circ} \mathrm{C}$ for $60 \mathrm{~s}$, followed by a final extension at $72^{\circ} \mathrm{C}$ for $30 \mathrm{~min}$. Fragmented sizes of PCR products were determined on an ABI3100-avant automatic sequencer (Applied Biosystems). Allele assignment was performed using GeneMapper v3.7.

Numerical analyses

\section{Genetic diversity within plots}

As a measurement of genetic variation Nei's unbiased gene diversity ( $H$; Nei 1978) was calculated as well as the number of multilocus genotypes per population $(G)$. Both genetic diversity estimators were calculated using the codes written by Werth et al. (2006a) in R (R Development Core Team 2004). 
Table 1 Environmental variables values and genetic diversity data of each one of the plots studied

\begin{tabular}{|c|c|c|c|c|c|c|c|c|c|}
\hline Patch & Plot & $\begin{array}{l}\text { Distance } \\
\text { from } \\
\text { river }\left(\mathrm{m}^{2}\right)\end{array}$ & $\begin{array}{l}\text { No. of } \\
\text { trees }\end{array}$ & $\begin{array}{l}\text { Mean } \\
\text { DBH } \\
(\mathrm{cm})\end{array}$ & $\begin{array}{l}\text { Cover of } \\
\text { L. pulmonaria } \\
\left(\mathrm{cm}^{2}\right)\end{array}$ & $\begin{array}{l}\text { No. of trees } \\
\text { occupied by } \\
\text { L. pulmonaria }\end{array}$ & $H$ & $G$ & $n$ \\
\hline Lillas-Beech 1 & 1 & 694.10 & 21 & 29.79 & 100 & 2 & 0.59 & 9 & 20 \\
\hline Lillas-Beech 1 & 2 & 285.43 & 22 & 30.30 & 6341 & 9 & 0.57 & 10 & 20 \\
\hline Lillas-Beech 1 & 3 & 354.00 & 24 & 28.60 & 1278 & 7 & 0.56 & 7 & 20 \\
\hline Lillas-Beech 2 & 4 & 642.46 & 40 & 20.84 & 9669 & 8 & 0.28 & 5 & 20 \\
\hline Lillas-Beech 2 & 5 & 144.70 & 28 & 19.46 & 3382 & 3 & 0.64 & 7 & 20 \\
\hline Lillas-Beech 2 & 6 & 660.66 & 35 & 19.06 & 1602 & 11 & 0.35 & 4 & 20 \\
\hline Lillas-Beech 2 & 7 & 719.64 & 22 & 32.32 & 3704 & 4 & 0.63 & 6 & 14 \\
\hline Lillas-Beech 2 & 8 & 128.75 & 42 & 22.19 & 3760 & 12 & 0.51 & 6 & 20 \\
\hline Lillas-Beech 2 & 9 & 192.26 & 35 & 20.26 & 5878 & 11 & 0.42 & 7 & 20 \\
\hline Lillas-Beech 2 & 10 & 502.25 & 44 & 19.62 & 26,105 & 18 & 0.36 & 5 & 20 \\
\hline Lillas-Beech 3 & 11 & 113.79 & 33 & 22.07 & 743 & 4 & 0.41 & 5 & 20 \\
\hline Zarzas-Beech 6 & 12 & 400.85 & 26 & 32.31 & 4552 & 8 & 0.43 & 7 & 19 \\
\hline Zarzas-Beech 7 & 13 & 198.93 & 21 & 31.01 & 4525 & 10 & 0.23 & 3 & 20 \\
\hline Zarzas-Beech 8 & 14 & 223.62 & 40 & 24.38 & 5179 & 10 & 0.43 & 7 & 20 \\
\hline Zarzas-Beech 9 & 15 & 215.62 & 13 & 60.88 & 56,301 & 12 & 0.63 & 9 & 20 \\
\hline Zarzas-Beech 10 & 16 & 424.58 & 35 & 23.95 & 2264 & 16 & 0.58 & 7 & 20 \\
\hline Zarzas-Beech 10 & 17 & 287.61 & 18 & 31.72 & 7056 & 9 & 0.48 & 6 & 20 \\
\hline Zarzas-Beech 11 & 18 & 27.65 & 23 & 32.29 & 13,943 & 21 & 0.64 & 9 & 20 \\
\hline Zarzas-Beech 12 & 19 & 516.76 & 26 & 29.43 & 17,378 & 10 & 0.50 & 5 & 20 \\
\hline Zarzas-Beech 12 & 20 & 542.74 & 13 & 49.22 & 291 & 2 & 0.58 & 12 & 20 \\
\hline Zarzas-Beech 13 & 21 & 63.71 & 23 & 27.54 & 8513 & 5 & 0.59 & 10 & 20 \\
\hline Zarzas-Beech 13 & 22 & 95.31 & 27 & 26.05 & 8784 & 18 & 0.50 & 6 & 20 \\
\hline Riaza-Beech 16 & 23 & 828.80 & 19 & 37.86 & 60,807 & 17 & 0.47 & 7 & 19 \\
\hline Riaza-Beech 16 & 24 & 745.58 & 7 & 74.02 & 3898 & 6 & 0.51 & 6 & 20 \\
\hline Riaza-Beech 17 & 25 & 600.04 & 41 & 22.49 & 24,613 & 25 & 0.25 & 3 & 17 \\
\hline Riaza-Beech 17 & 26 & 643.06 & 45 & 24.99 & 10,260 & 10 & 0.44 & 9 & 20 \\
\hline Riaza-Beech 17 & 27 & 490.58 & 25 & 33.44 & 5948 & 17 & 0.65 & 8 & 20 \\
\hline Riaza-Beech 17 & 28 & 223.53 & 21 & 39.51 & 6879 & 11 & 0.49 & 6 & 20 \\
\hline Riaza-Beech 18 & 29 & 73.20 & 72 & 16.37 & 16,701 & 22 & 0.16 & 3 & 20 \\
\hline Riaza-Beech 19 & 30 & 463.28 & 25 & 27.87 & 17,196 & 8 & 0.38 & 4 & 14 \\
\hline Riaza-Beech 21 & 31 & 1506.72 & 25 & 28.46 & 5905 & 11 & 0.16 & 3 & 20 \\
\hline Riaza-Beech 21 & 32 & 1419.66 & 23 & 35.05 & 4790 & 10 & 0.59 & 9 & 20 \\
\hline Riaza-Beech 22 & 33 & 1351.04 & 16 & 47.23 & 7307 & 9 & 0.69 & 11 & 20 \\
\hline Riaza-Beech 23 & 34 & 1996.65 & 9 & 66.45 & 4431 & 5 & 0.42 & 6 & 20 \\
\hline Lillas-Oaks 24 & 35 & 85.57 & 29 & 20.01 & 78,276 & 27 & 0.50 & 9 & 20 \\
\hline Lillas-Oaks 25 & 36 & 339.79 & 48 & 17.04 & 1350 & 4 & 0.60 & 8 & 20 \\
\hline Lillas-Oaks 26 & 37 & 9.64 & 24 & 28.20 & 20,099 & 19 & 0.27 & 4 & 18 \\
\hline Lillas-Oaks 26 & 38 & 37.78 & 60 & 18.05 & 14,439 & 17 & 0.45 & 6 & 20 \\
\hline Lillas-Oaks 27 & 39 & 132.95 & 122 & 11.22 & 6598 & 33 & 0.34 & 2 & 20 \\
\hline Zarzas-Oaks 28 & 40 & 459.46 & 63 & 15.84 & 5641 & 6 & 0.55 & 10 & 20 \\
\hline Zarzas-Oaks 29 & 41 & 1520.11 & 82 & 14.65 & 15,640 & 42 & 0.00 & 1 & 20 \\
\hline Zarzas-Oaks 30 & 42 & 179.26 & 33 & 21.19 & 91,384 & 33 & 0.62 & 10 & 20 \\
\hline
\end{tabular}


Table 1 continued

\begin{tabular}{lccccccccc}
\hline Patch & Plot & $\begin{array}{l}\text { Distance } \\
\text { from } \\
\text { river }\left(\mathrm{m}^{2}\right)\end{array}$ & $\begin{array}{l}\text { No. of } \\
\text { trees }\end{array}$ & $\begin{array}{l}\text { Mean } \\
\mathrm{DBH} \\
(\mathrm{cm})\end{array}$ & $\begin{array}{l}\text { Cover of } \\
\text { L. pulmonaria } \\
\left(\mathrm{cm}^{2}\right)\end{array}$ & $\begin{array}{l}\text { No. of trees } \\
\text { occupied by } \\
\text { L. pulmonaria }\end{array}$ & $H$ & $G$ & $n$ \\
\hline Zarzas-Oaks 30 & 43 & 82.93 & 37 & 21.94 & 128,411 & 30 & 0.43 & 7 & 20 \\
Zarzas-Oaks 31 & 44 & 257.06 & 38 & 17.38 & 4894 & 9 & 0.64 & 10 \\
\hline
\end{tabular}

$H$ represents Nei's unbiased gene diversity, $G$ represents the number of multilocus genotypes per plot, $n$ represents the number of individuals genotyped per plot

Table 2 Environmental variables values of patch forest fragments and genetic diversity of L. pulmonaria

\begin{tabular}{|c|c|c|c|c|c|}
\hline Patch & Plots sampled & Patch area (ha) & Patch connectivity & $\%$ Matrix pine perimeter & $n$ \\
\hline Lillas-Beech 1 & 3 & 35.01 & 55.16 & 9.25 & 60 \\
\hline Lillas-Beech 2 & 7 & 209.79 & 30.80 & 11.37 & 134 \\
\hline Lillas-Beech 3 & 1 & 2.40 & 30.80 & 0.00 & 20 \\
\hline Zarzas-Beech 6 & 1 & 5.67 & 78.18 & 0.00 & 19 \\
\hline Zarzas-Beech 7 & 1 & 2.84 & 84.70 & 0.00 & 20 \\
\hline Zarzas-Beech 8 & 1 & 0.84 & 87.63 & 0.00 & 20 \\
\hline Zarzas-Beech 9 & 1 & 3.07 & 78.17 & 21.91 & 20 \\
\hline Zarzas-Beech 10 & 2 & 7.52 & 74.44 & 10.79 & 40 \\
\hline Zarzas-Beech 11 & 1 & 0.74 & 78.17 & 34.06 & 20 \\
\hline Zarzas-Beech 12 & 2 & 10.11 & 52.98 & 7.71 & 40 \\
\hline Zarzas-Beech 13 & 2 & 45.06 & 29.45 & 1.95 & 40 \\
\hline Riaza-Beech 16 & 2 & 12.72 & 47.22 & 0.00 & 39 \\
\hline Riaza-Beech 17 & 4 & 59.85 & 42.80 & 0.00 & 77 \\
\hline Riaza-Beech 18 & 1 & 13.70 & 80.33 & 0.00 & 20 \\
\hline Riaza-Beech 19 & 1 & 8.64 & 70.75 & 0.00 & 14 \\
\hline Riaza-Beech 21 & 2 & 11.31 & 50.28 & 0.00 & 40 \\
\hline Riaza-Beech 22 & 1 & 6.75 & 31.21 & 0.00 & 20 \\
\hline Riaza-Beech 23 & 1 & 2.55 & 40.86 & 0.00 & 20 \\
\hline Lillas-Oaks 24 & 1 & 7.53 & 30.80 & 0.00 & 20 \\
\hline Lillas-Oaks 25 & 1 & 5.78 & 30.80 & 0.00 & 20 \\
\hline Lillas-Oaks 26 & 2 & 73.56 & 30.80 & 12.56 & 38 \\
\hline Lillas-Oaks 27 & 1 & 28.36 & 92.23 & 61.71 & 20 \\
\hline Zarzas-Oaks 28 & 1 & 14.25 & 27.25 & 98.48 & 20 \\
\hline Zarzas-Oaks 29 & 1 & 21.39 & 74.88 & 77.54 & 20 \\
\hline Zarzas-Oaks 30 & 2 & 17.70 & 78.17 & 77.42 & 40 \\
\hline Zarzas-Oaks 31 & 1 & 4.52 & 65.95 & 26.66 & 14 \\
\hline
\end{tabular}

Patch names follow the nomenclature introduced by Belinchón et al. (2009), $n$ represents the total number of individual sampled in each patch

Generalized Linear Mixed Model (GLMMs, Breslow and Clayton 1993) was implemented to evaluate the effect of environmental variables (mean dbh, patch connectivity, percentage of pine matrix and cover of L. pulmonaria) on the genetic diversity of L. pulmonaria within plots. This modelling approach was chosen because our data had an unbalanced and hierarchical structure with plots nested within patches. A hierarchical data 
structure implies a correlation between data points at different scales, inflating the error degrees of freedom and increasing the chance of making a Type I error. To overcome these problems, we analyzed the data using a multilevel approach, considering when necessary plots and patches as random factors and applying mixed modelling (Verbeke and Molenberghs 1997). Predictors were included as explanatory variables (fixed factors) and patch and plot were included as random sources of variation. Because the data tended to be over-dispersed in some cases, we used the quasi-likelihood approach to overcome possible difficulties (Guisan et al. 2002). For $L$. pulmonaria genetic diversity ( $H$ and $G$ ) we fitted the mixed models using the normal response, an "identity" link function, and setting the variance to "1-mean". Effects of random factors were tested using the Wald Z-statistic test. All GLMM computations were performed using SAS Macro program GLIMMIX, which iteratively calls SAS Procedure Mixed until convergence (GLIMMIX ver. 8 for SAS/STAT; available at http://www.sas.com.techsup/download/stat/). Since the number of patches was limited (44) we did not include other hierarchized levels for the host tree diversity (beech and oak). For exploring differences between the two host species we built a simpler linear model at this level.

\section{Genetic structure}

To estimate differences among the three regions (Zarza Valley, Lillas Valley and the northern slope of the Ayllón Mountains) a genetic distance matrix of pairwise Fst values was used to perform hierarchical analysis of molecular variance (AMOVA). We also performed a second AMOVA to test for genetic structure correlated to forest patches. AMOVAs were carried out using ARLEQUIN 3.11 software (http://lgb.unige.ch/arlequin/), assessing significance by 10,000 permutations.

Additionally, we performed a Multiple Regression on distance Matrices (MRM) to identify environmental variables that best predicted genetic differentiation among populations taking into account the spatial structure of the populations. We used a MRM lag matrices model to test the percent of variation in population pairwise genetic distance matrix (Fst, Reynolds et al. 1983) explained by the spatial structure and the differences among environmental variables between populations. Population genetic distance matrix of pairwise $F s t$ values was also calculated using ARLEQUIN 3.11. The MRM is a multiple regression of a response distance matrix (pairwise $F s t$ ) on environmental and spatial explanatory distance matrices (Lichstein 2007). Permutation of MRM environmental models were performed using five environmental distance matrices containing the absolute values of inter-population differences for the following variables: distance from the river, type of forest (host tree), connectivity and average dbh. Each distance matrix (Dy) included 946 distance values (44 populations Dy $=n(n-1) / 2, n=$ populations). For geographic distance, we constructed 10 lag distance classes, following Sturge's rule (Legendre and Legendre 1998). The MRM method allows each environmental variable to be represented by its own distance matrix providing an improved correlation among genetic structure and environmental variables (Lichstein 2007). Therefore, we opted to employ the MRM method. Two models were implemented to estimate the partitioning of variation in genetic distance into two components: pure environmental (E) and spatial-environmental (S-E). The first model searches over all possible combinations of five environmental distance matrices, to identify the set that explains the highest level of variation in the population pairwise $F$ st distance. The second model includes the significant environmental variables selected by the first model and the 10 lag distance classes. Permutation test for MRM models were implemented using forward and backward selections in PERMUTE! 3.4 
(Legendre et al. 1994) with a $p$ to enter or to remove of $0.05 / \mathrm{X}$ using the Bonferroni correction. In all cases, forward selection and backward elimination chose the same variables.

\section{Results}

Genetic diversity within plots

A total of 855 thalli of $L$. pulmonaria from 44 plots (31 forest patches) were genotyped at three microsatellite loci. A total of 47 different multilocus genotypes were detected. Genetic diversity estimated as $H$ ranged from 0.00 to 0.69 (Table 1). Values of genetic diversity $(H$ and $G$ ) were not affected neither by type of forest (beech or oak) or patch size (Figs. 1,2). The minimum value for $H$ and $G$ were found in a plot with oak trees in the Zarzas valley region (Zarzas-Oaks 29, Table 1). Low diversity values were also found in the other regions and in both types of forests (e.g. Zarzas-Beech 7, Riaza-Beech 17 and Lillas-Oaks 26). The highest value of both genetic diversity estimators was found in a plot with beech trees in the Riaza region (Riaza-Beech 22, Table 1). The linear generalized models indicated that average tree diameter per plot was the most important predictor of the genetic diversity estimated as $H$ but not of the number of multilocus genotypes in the plot $G$ (Table 3 ). Gene diversity $H$ increased significantly with the average tree diameter in plots. Neither the forest patch connectivity nor the perimeter of surrounding pine afforestation accounted for the variation in genetic diversity. In both cases the residual values were significant $(H$ residual: $\mathrm{Z}=4.22, P<0.0001 ; G$ residual: $\mathrm{Z}=4.25$, $P<0.0001)$.

\section{Genetic structure}

AMOVA results showed that most of the variation $(76.1 \%)$ was found within the $400 \mathrm{~m}^{2}$ demes (plots), followed by significant variation among demes within regions $(24.1 \%)$, while molecular variation among regions was not statistically significant (Table 4). There was also a weak but significant genetic differentiation among forest patches $(3.4 \%$; Table 5).

Multiple regression analyses results are shown in Table 6. Partitioning the variance strictly into geographic distance (10 lag distance classes) explained $1.3 \%$ of the pairwise Fst; environmental variables explained $8.9 \%$ and the combined model with both distance
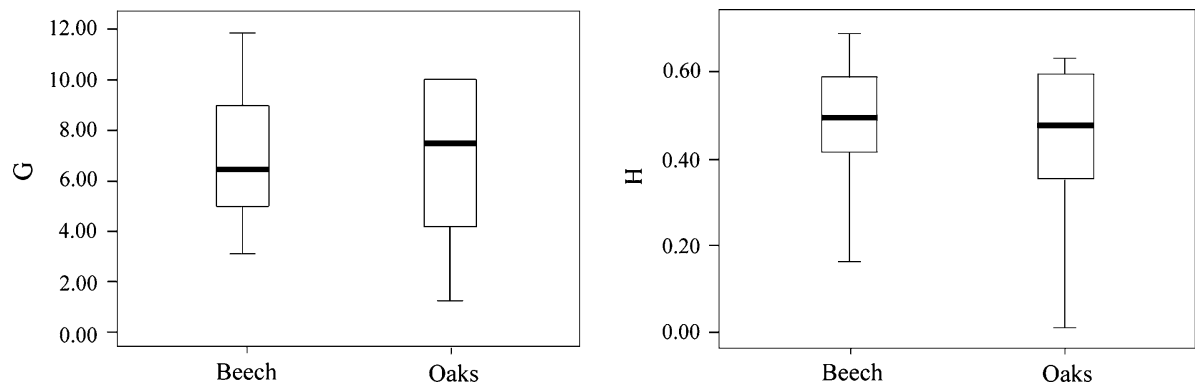

Fig. 1 Genetic diversity ( $H$ and $G$ ) by type of tree host studied 
Fig. 2 Relationship between patch size (area in $\mathrm{m}^{2}$ ) and genetic diversity estimators

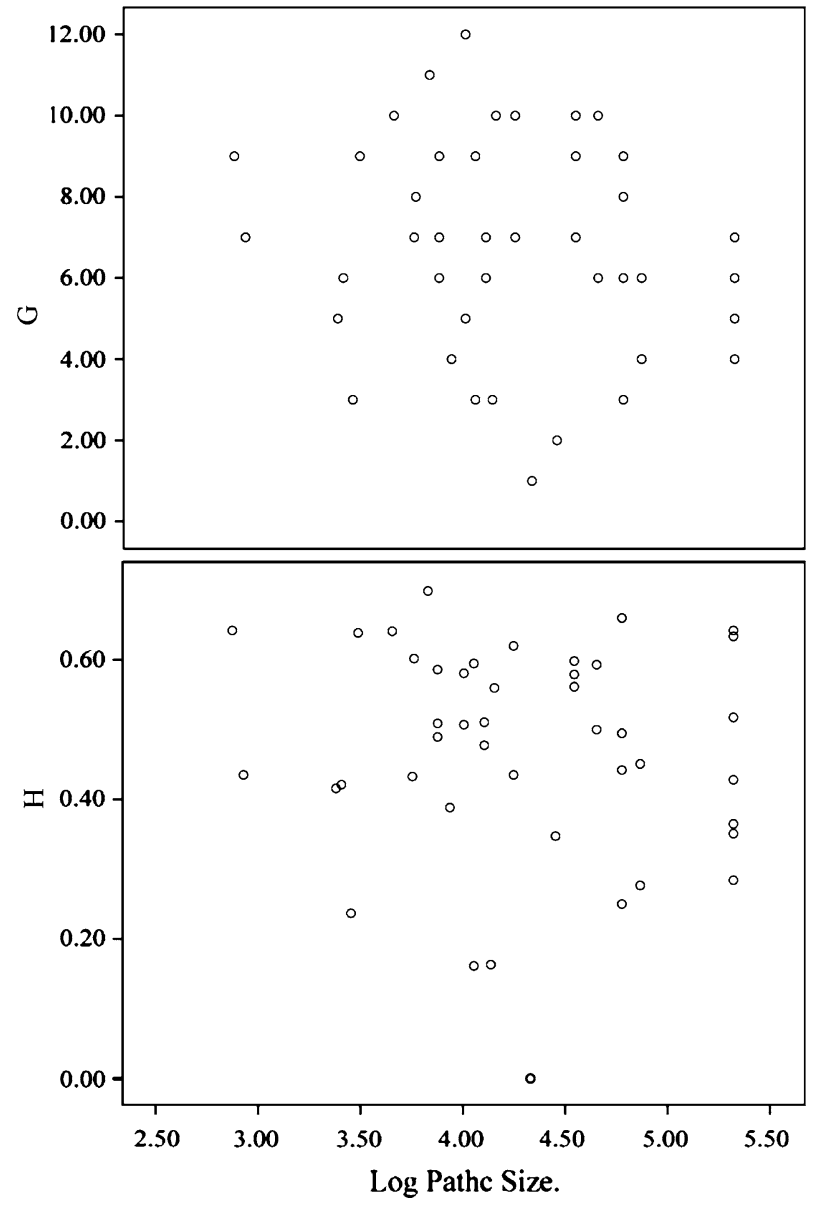

Table 3 Results from generalized linear mixed model examining Lobaria pulmonaria genetic diversity $(H$ and $G)$ in the System Central Range in Spain

\begin{tabular}{|c|c|c|c|c|c|c|}
\hline \multirow[t]{2}{*}{ Fixed factors } & \multicolumn{3}{|l|}{$H$} & \multicolumn{3}{|l|}{$G$} \\
\hline & Estimate $( \pm \mathrm{SE})$ & $F$ & $P$ & Estimate $( \pm \mathrm{SE})$ & $F$ & $P$ \\
\hline \multicolumn{7}{|l|}{ Patch level } \\
\hline Connectivity & $0.00240(0.0005)$ & 0.20 & 0.66 & $0.00139(0.009)$ & 0.02 & 0.88 \\
\hline$\%$ Pine & $0.00189(0.0019)$ & 2.99 & 0.09 & $0.02700(0.019)$ & 1.91 & 0.18 \\
\hline \multicolumn{7}{|l|}{ Plot level } \\
\hline Mean dbh & $0.03610(0.0017)$ & 4.17 & 0.04 & $0.05262(0.031)$ & 2.78 & 0.10 \\
\hline L. pulmonaria cover & $0.00006(0.000)$ & 0.55 & 0.46 & $0.00002(0.000)$ & 0.02 & 0.89 \\
\hline
\end{tabular}

Data represents the Wald-type $F$-statistic (Wald Z-statistic for random factors). Boldfaced values represent significant factors

and environmental variables explained 10\% (Table 6). Only a negligible spatial autocorrelation of genetic diversity among subpopulations between the 1429-2856 m of distance was found (lags 3 and 4; Table 6). 
Table 4 Analysis of molecular variance (AMOVA) with regions as cofactor

\begin{tabular}{lrccrr}
\hline Source of variation & D.f & Sum of squares & Variance & $\%$ & $P$ \\
\hline Among regions & 2 & 8.73 & 0.00 & 0.28 & $>0.05$ \\
Among demes within regions & 41 & 207.44 & 0.22 & 24.17 & $<0.001$ \\
Within demes & 811 & 572.36 & 0.70 & 76.10 & $<0.001$ \\
Total & 854 & 788.53 & 0.92 & & \\
\hline
\end{tabular}

Table 5 Analysis of molecular variance (AMOVA) with forest patch as cofactor

\begin{tabular}{lccccc}
\hline Source of variation & D.f & Sum of squares & Variance & $\%$ & $P$ \\
\hline Among forest patches & 26 & 140.695 & 0.032 & 3.46 & $<0.05$ \\
Among demes within forest patches & 17 & 75.479 & 0.192 & 20.54 & $<0.001$ \\
Within demes & 811 & 572.36 & 0.706 & 76.10 & $<0.001$ \\
Total & 854 & 788.53 & 0.929 & & \\
\hline
\end{tabular}

Table 6 Multiple regression analysis (MRM) of environmental and space-environmental models

Standardized regression coefficients from multiple regressions on distance matrices, with pairwise genetic distance (Fst) as the response variable. The geographic distance (as lag distance classes) and interplot variation in seven environmental variables are the explanatory variables. A Bonferroni-corrected $P$-value of 0.005 was used in forward and backward selection to derive the final model from the full model

Boldfaced values represent significant factors

a Lag distances, values in brackets represent: (max lag distance (m)/frequency)

\begin{tabular}{|c|c|c|}
\hline Variables & Coefficient & $P$ \\
\hline \multicolumn{3}{|l|}{ Spatial model (S) } \\
\hline Lag $1^{a}(714 / 63)$ & 0.03 & 0.203 \\
\hline Lag $2^{\mathrm{a}}(1428 / 116)$ & 0.06 & 0.132 \\
\hline $\operatorname{Lag} 3^{a}(2142 / 129)$ & 0.12 & 0.005 \\
\hline $\operatorname{Lag} 4^{\mathrm{a}}(2856 / 212)$ & 0.14 & 0.003 \\
\hline Lag $5^{\mathrm{a}}(3570 / 159)$ & 0.09 & 0.140 \\
\hline Lag $6^{\mathrm{a}}(4284 / 154)$ & 0.07 & 0.196 \\
\hline $\operatorname{Lag} 7^{\mathrm{a}}(4998 / 72)$ & 0.06 & 0.194 \\
\hline $\operatorname{Lag} 8^{\mathrm{a}}(5712 / 27)$ & 0.06 & 0.154 \\
\hline $\operatorname{Lag} 9^{\mathrm{a}}(6424 / 11)$ & 0.05 & 0.165 \\
\hline $\operatorname{Lag} 10^{\mathrm{a}}(7140 / 63)$ & 0.05 & 0.165 \\
\hline $\mathrm{r}^{2}=0.013$ & & 0.001 \\
\hline \multicolumn{3}{|l|}{ Environmental model (E) } \\
\hline Distance from river & 0.24 & 0.001 \\
\hline dbh & 0.13 & 0.001 \\
\hline Connectivity & 0.11 & 0.005 \\
\hline Host species & 0.15 & 0.001 \\
\hline$\%$ Matrix pine perimeter & 0.24 & 0.055 \\
\hline$r^{2}=0.089$ & & 0.001 \\
\hline \multicolumn{3}{|c|}{ Environmental + Spatial model $(\mathrm{S}-\mathrm{E})$} \\
\hline Distance from river & 0.24 & 0.001 \\
\hline $\mathrm{dbh}$ & 0.13 & 0.001 \\
\hline Connectivity & 0.11 & 0.005 \\
\hline Host species & 0.15 & 0.001 \\
\hline Lag $3^{a}(2142 / 129)$ & 0.12 & 0.005 \\
\hline Lag $4^{\mathrm{a}}(2856 / 212)$ & 0.14 & 0.003 \\
\hline$r^{2}=0.010$ & & 0.001 \\
\hline
\end{tabular}




\section{Discussion}

Genetic diversity within populations

The ecological requirements and population structure of Lobaria pulmonaria in the Mediterranean forest landscape (Martínez et al. 2006; Belinchón et al. 2009), together with the continuous reduction of suitable habitat of this species, suggest that the species could exhibit low levels of genetic diversity. However, the populations of this lichen in the study area exhibited relatively high values of genetic diversity $(H)$ in most forest patches (mean value of $H=0.46 ; \mathrm{SD}=0.15$ ). The levels of genetic diversity that we observed were similar to values reported from Central Europe (Walser et al. 2005; Werth et al. 2006a) despite the fact that the latter are generally larger and have a more continuous distribution than the marginal populations studied (Martínez et al. 2006). We expected that small forest patches with little connectivity would exhibit low values of genetic diversity and higher levels of differentiation relative to populations of connected forest patches. However, no evidence was found for a consistent reduction in genetic diversity in L. pulmonaria populations in isolated forest fragments (Table 3; Fig. 2). Predictors related to landscape attributes of the remnants such as connectivity together with the nature of the matrix had no significant effects on the genetic diversity of L. pulmonaria (Table 3).

We found no relationship between total cover of Lobaria pulmonaria in the plot and the genetic variation (Table 3). Population genetics theory predicts that fragmentation into isolated, discrete subpopulations composed of relatively few individuals contributes to a depletion of overall genetic diversity (Ellstrand and Elam 1993). However, our results only showed that habitat quality (i.e. patch longevity: estimated as mean tree dbh) exerted some influence on genetic diversity. Negative effects of landscape fragmentation have been previously reported for bryophytes (Wilson and Provan 2003; Wyatt et al. 2005). However, recent studies did not find a reduction in population genetic diversity due to forest fragmentation in lichens and bryophytes species associated to well preserve forest (Zartman et al. 2006; Pohjamo et al. 2008; Lättman et al. 2009).

The genetic diversity found within populations likely results from cumulative effects of both historical and present processes (Hewitt 2000). Present processes include habitat alteration and its consequence on the local climate, which may influence growth and reproduction of L. pulmonaria. Lobaria pulmonaria reproduces either by sexual (microscopic spores of the mycobiont) or vegetative propagules (contains both symbionts), such as soredia and/or isidioid soredia (Büdel and Scheidegger 2008). The vegetative propagules are better suited to the establishment of new individuals at short distances, while spores are more effective as long distance propagules (Buschbom 2007; Scheidegger and Werth 2009). Although L. pulmonaria potentially exhibit these two reproductive strategies, our populations completely lacked sexual reproduction. Sexual reproduction of L. pulmonaria is very rare in the Mediterranean region of Spain (1.2\% of 5253 individual from 16 populations along the Iberian Peninsula has sexual structures, Martínez et al. unpubl. data) but this lack have no negative effects on genetic diversity 50 years after partial habitat transformation into pine forests and heathland. Even with the limited dispersal potential, fragmentation of the forest landscape did not cause a reduced genetic diversity in L. pulmonaria at the plot level, since relatively high levels of genetic diversity were irrespective of forest patch size and patch connectivity. Because genetic drift effects in fragmented habitats accumulate by the number of generations, it is expected that adverse genetic consequences are more notable in populations of short-lived species relative to long-lived species (Young et al. 1996). Therefore we conclude that the long generation 
time of this species has prevented demes from genetic drift since the fragmentation of the forest landscape in the 1960s. Previous studies shown that sexual reproduction of $L$. pulmonaria is related to higher genetic diversity within populations (Zoller et al. 1999). However, vegetative reproduction is able to maintain genotypes in large populations, and may even allow the accumulation of new genotypes by mutation events. Therefore, vegetative reproduction may buffer the genetic effect of habitat fragmentation by delaying the impact between generations (Honnay and Bossuyt 2005). Thus, the values of $H$ and $G$ observed in this study still largely reflect the situation before the fragmentation 50 years ago since this period is still within the range of one generation of the lichen and its host trees. Our results are congruent with those reported by Belinchón et al. (2009), who concluded that L. pulmonaria is sensitive to a decrease in habitat quality, with tree size being the most important predictor for the maintenance of its populations in Mediterranean forests. Habitat quality estimated as the age of the patches is a critical factor in L. pulmonaria performance (Belinchón et al. 2009) and also for the genetic diversity $(H)$. It is important to note that the variation in genetic diversity levels and genetic structure of lichen species may be also influenced by photobiont availability and specificity. Further studies on the genetic structure and diversity of the photobiont in L. pulmonaria populations are necessary to provide information about the mode of symbiont transmission. The establishment of a lichen from fungal spores is only effective in the presence of the photobiont partner. If the fungal partner is highly specific the most effective dispersal mechanisms will be through vegetative propagules. Future studies on the mode of simbiont transmission will give us more information about the response of $L$. pulmonaria to habitat fragmentation.

\section{Spatial structure}

The AMOVA results indicated that most of the total genetic variation was due to differences among individuals within demes with negligible differentiation among the three regions sampled in spite of the management history and conservation status (Tables 4, 5). However, we detected a limited but significant population structure of Lobaria pulmonaria at small scale. More specifically, we found that at forest patch level populations are poorly structured (Table 5). A weak but significant isolation-by-distance in this species was previously reported in central Europe (Werth et al. 2007). Due to the relatively high level of fragmentation and the management history of this landscape, we expected higher levels of differentiation by low gene flow among remnant forests and a strong effect due to genetic drift. The pine afforestation is not an appropriate habitat for this species; therefore we presumed that it would be acting as a barrier to the gene flow.

The spatial model only explained $1.3 \%$ of the genetic differentiation, which, although statistically significant, has a low ecological relevance (Table 6). The results of MRM showed that none of the landscape features alone explained the observed genetic differentiation. The best model explained $10 \%$ of the total variance (S-E, Table 6). This spatially unstructured pattern reflects the connectedness among forest stands that occurred in this Mediterranean landscape before fragmentation. The analysis also identified a combination of environmental factors that appeared to drive L. pulmonaria gene flow in this landscape (Table 6). Thus, distances to the river and forest connectivity affect slightly the population genetic structure, suggesting that well preserved forest fragments close to the rivers harbour slightly differentiated populations. Belinchón et al. (2009) also found that the more humid and stable conditions close to rivers profoundly affected the performance of this species. In addition, mean tree diameter differences have a weak but also significant 
influence in the spatial genetic structure of $L$. pulmonaria (Table 6). This indicates that plots maintaining old trees carry L. pulmonaria genetically more similar than those patches that are geographically close but with younger trees. It suggests that the genetic configuration of young patches could be explained by rare random colonization events from old patches, followed by clonal spread of the recently established individuals (Werth et al. 2006a; Wagner et al. 2006). Thus the effective dispersal processes operating in the past when the old forest habitat was more continuous, has only slightly been reduced due to habitat fragmentation. The fact that forest age is a component that influences the genetic structure of this epiphytic species seems to confirm the hypothesis that time is more important than spatial factors in dispersal processes for long-lived species as L. pulmonaria (Young et al. 1996). The detection of low levels of genetic structure are consistent with the results of Werth et al. (2006a) and Werth et al. (2007) who demonstrated the existence of a weak but significant isolation by distance in L. pulmonaria in a disturbed landscape in Central Europe. The significant fine scale genetic structure was attributed to spatial clustering of clones along with significant genetic differentiation among populations (Wagner et al. 2005; Werth et al. 2006a, b), suggesting that dispersal in L. pulmonaria is rather effective, but not spatially unrestricted (Scheidegger and Werth 2009). Other studies on lichens species have reported dispersal limitations at small spatial scales with a significant spatial structure (Walser 2004; Cassie and Piercey-Normore 2008) or the absence of long range dispersal (Walser et al. 2005). By contrast and more frequently, studies showed that propagules of lichen-forming fungi are widely and effectively dispersed at both small and large spatial scales and thus populations are not structured at and below the landscape level (Palice and Printzen 2004; Buschbom 2007; Werth and Sork 2008; Lättman et al. 2009; Otálora et al. 2010).

Habitat quality of the remnant forest fragments, surrounding matrix and moisture conditions within the forest are critical in the performance and behaviour of Lobaria pulmonaria in Mediterranean mountain forests (Belinchón 2009; Belinchón et al. 2009). Our genetic study emphasizes that habitat quality is the most important factor for the longterm maintenance of L. pulmonaria. However, in this study we didn't find any effects of the surrounding matrix on genetic diversity and structure, suggesting that fragmentation effects tend to be observed first in the ecological features (occurrence and cover) than in the genetic component of the populations (Caughley 1994; Zartman et al. 2006; Kramer et al. 2008). Our results showed that in the Mediterranean landscape the populations of this lichen species are structured by a gradient of habitat quality. In conclusion, the levels of genetic diversity and differentiation in L. pulmonaria are the result of high levels of gene flow within populations and rapidly declining levels of gene flow with increasing distance among populations within forest patches. The levels of genetic differentiation found between forest patches reflect historic dispersal before the forest landscape was altered by forest management that led to the current level of fragmentation. The relatively high level of genetic diversity of the species in old forest patches, regardless of patch size, indicate that habitat quality, i.e. the availability of old trees in a highly structured forest stand is shaping the population size and distribution pattern of this species and its associated species rich lichen community. Thus, conservation and recovery programmes of Mediterranean Mountain forests have to prioritize habitat quality of old forest patches.

Acknowledgments We thank J. Dimas, M. Herrera, M. Prieto, and R. López for help with fieldwork. We also thank C. Cornejo for technical support in the molecular Lab at WSL. Special thanks go to G. Cerezo and the Natural Park of Hayedo de Tejera Negra for granting permission to work in the park. We finally thank two anonymous reviewers provided helpful comments that improve this manuscript. This research was 
supported by the Dirección General del Medio Natural, Comunidad Autónoma de Castilla-La Mancha, Ministerio de Educación y Ciencia of Spain (project CGL2007-66066-C04-04/BOS) and Universidad Rey Juan Carlos of Madrid ("Estancia breves").

\section{References}

Belinchón (2009) Efecto de la fragmentación de los bosques Mediterráneos sobre las comunidades de líquenes epífitos. Ph.D. Dissertation, Department of Biology and Geology, Universidad Rey Juan Carlos, Madrid

Belinchón R, Martínez I, Otálora MAG et al (2009) Fragment quality and matrix affect epiphytic performance in a Mediterranean forest landscape. Am J Bot 96:974-1982

Breslow NE, Clayton DC (1993) Approximate inference in generalized linear mixed models. J Am Stat Assoc 88:9-25

Büdel B, Scheidegger C (2008) Thallus morphology and anatomy. In: Nash TH (ed) Lichen Biology. Cambridge University Press, Cambridge, p 40

Buschbom J (2007) Migration between continents: geographical structure and long-distance gene flow in Porpidia flavicunda (lichen-forming Ascomycota). Mol Ecol 16:1835-1846

Cassie DM, Piercey-Normore MD (2008) Dispersal in a sterile lichen-forming fungus, Thamnolia subuliformis (Ascomycotina: Icmadophilaceae). Can J Bot 86:751-762

Caughley G (1994) Directions in conservation biology. J Anim Ecol 63:215-244

Crespo A, Blanco O, Hawksworth DL (2001) The potential of mitochondrial DNA for establishing generic concepts in the parmeliod lichens. Taxon 50:807-819

Ellstrand NC, Elam DR (1993) Population genetic consequences of small population size: implications for plant conservation. Annu Rev Ecol Evol Syst 24:217-242

Fahrig L (2003) Effects of habitat fragmentation on biodiversity. Annu Rev Ecol Evol Syst 34:487-515

Guisan A, Edwards TC Jr, Hastie T (2002) Generalized linear and generalized additive models in studies of species distributions: setting the scene. Ecol Model 157:89-100

Hamrick JL (2004) Response of trees to global environmental changes. For Ecol Manag 197:323-335

Hanski I, Gaggiotti OE (2004) Ecology genetics and evolution of metapopulations. Elsevier, San Diego

Henle K, Lindenmayer DB, Margules CR et al (2004) Species survival in fragmented landscapes: where are we now? Biodivers Conserv 13:1-8

Hernández JE, Sainz H (1978) Ecología de los hayedos meridionales ibéricos: el macizo de Ayllón. Ministerio de Agricultura, Madrid

Hewitt GM (2000) The genetic legacy of the quaternary ice ages. Nature 405:907-913

Hoehn M, Sarre SD, Henle K (2007) The tales of two geckos: does dispersal prevent extinction in recently fragmented populations? Mol Ecol 16:3299-3312

Holderegger R, Wagner HH (2008) Landscape genetics. Bioscience 58:199-208

Honnay O, Bossuyt B (2005) Prolonged clonal growth: escape route or route to extinction? Oikos 108:427-432

Johansson P, Ehrlén J (2003) Influence of habitat quantity, quality and isolation on the distribution and abundance of two epiphytic lichens. J Ecol 91:213-221

Kramer AT, Ison JL, Ashley MV, Howe HF (2008) The paradox of forest fragmentation genetics. Conserv Biol 22:878-885

Lättman H, Lindblom L, Mattsson JE et al (2009) Estimating the dispersal capacity of the rare lichen Cliostomum corrugatum. Biol Conserv 142:1870-1878

Legendre P, Legendre L (1998) Numerical ecology, 2nd edn. Elsevier Science, Amsterdam

Legendre P, Lapointe FJ, Casgrain P (1994) Modeling brain evolution from behavior: a permutational regression approach. Evolution 48:1487-1499

Lichstein JW (2007) Multiple regression on distance matrices: a multivariate spatial analysis tool. Plant Ecol 188:117-131

Löbel S, Snäll T, Rydin H (2006) Metapopulation processes in epiphytes inferred from patterns of regional distribution and local abundance in fragmented forest landscapes. J Ecol 94:856-868

Löbel S, Snäll T, Rydin H (2009) Mating system, reproduction mode and diaspore size affect metacommunity diversity. J Ecol 97:176-185

Manel S, Schwartz MK, Luikart G, Taberlet P (2003) Landscape genetics: combining landscape ecology and population genetics. Trends Ecol Evol 18:189-197

Martínez I, Carreño F, Escudero A, Rubio A (2006) Are threatened lichen species well-protected in Spain? Effectiveness of a protected areas network. Biol Conserv 133:500-511 
Münzbergová Z, Herben T (2005) Seed, dispersal, microsite, habitat and recruitment limitation-identification of terms and concepts in studies of limitations. Oecologia 145:1-8

Nei M (1978) Estimation of average heterozygosity and genetic distance from a small number of individuals. Genetics 89:538-590

Nielsen SE, Stenhouse GB, Boyce MS (2006) A habitat-based framework for grizzly bear conservation in Alberta. Biol Conserv 130:217-229

Otálora MAG, Martínez I, Aragón G, Molina MC (2010) Phylogeography and divergence date estimates of a lichen species complex with a disjunct distribution pattern. Am J Bot 97:216-223

Palice Z, Printzen C (2004) Genetic variability in tropical and temperate populations of Trapeliopsis glaucolepidea: evidence against long-range dispersal in a lichen with disjunct distribution. Mycotaxon 90:43-54

Pohjamo M, Korpelainen H, Kalinauskait N (2008) Restricted gene flow in the clonal hepatic Trichocolea tomentella in fragmented landscapes. Biol Conserv 141:204-1217

R Development Core Team (2004) R: a language and environment for statistical computing. URL: http://www.R-project.org.

Reynolds J, Weir BS, Cockerham CC (1983) Estimation for the coancestry coefficient: basis for a short-term genetic distance. Genetics 105:767-779

Ries L, Fletcher RJ Jr, Battin J, Sisk TD (2004) Ecological responses to habitat edges: mechanisms, models, and variability explained. Annu Rev Ecol Evol Syst 35:491-522

Scheidegger C, Werth S (2009) Conservation strategies for lichens: insights from population biology. Fungal Biol Rev 23:55-66

Schmuki C, Vorburger C, Runciman D et al (2006) When log-dwellers meet loggers: impacts of forest fragmentation on two endemic log-dwelling beetles in southeastern Australia. Mol Ecol 15:1481-1492

Sjöberg K, Ericson L (1992) Forested and open wetland complexes. In: Hansson L (ed) Ecological principles of nature conservation applications in temperate and boreal environments. Elsevier, New York, p 326

Snäll T, Hagström A, Rudolphi J, Rydin H (2004) Distribution pattern of the epiphyte Neckera pennata on three spatial scales-importance of past landscape structure, connectivity and local conditions. Ecography 27:757-766

Templeton AR, Shaw K, Routmon E, Davis SK (1990) Genetic consequences of habitat fragmentation. Annu Mo Bot Gard 77:13-27

Verbeke G, Molenberghs G (1997) Linear mixed models in practice: a SAS-oriented approach lecture notes in statist. Springer, New York

Wagner HH, Holderegger R, Werth S et al (2005) Variogram analysis of the spatial genetic structure of continuous populations using multilocus microsatellite data. Genetics 169:1739-1752

Wagner HH, Werth S, Kalwij JM et al (2006) Modelling forest recolonization by an epiphytic lichen using a landscape genetic approach. Landsc Ecol 21:849-865

Walser JC (2004) Molecular evidence for limited dispersal of vegetative propagules in the epiphytic lichen Lobaria pulmonaria. Am J Bot 91:1273-1276

Walser JC, Sperisen C, Soliva M, Scheidegger C (2003) Fungus specific microsatellite primers of lichens: application for the assessment of genetic variation on different spatial scales in Lobaria pulmonaria. Fungal Genet Biol 40:72-82

Walser JC, Gugerli F, Holderegger R et al (2004) Recombination and clonal propagation in different populations of the lichen Lobaria pulmonaria. Heredity 93:322-329

Walser JC, Holderegger R, Gugerli F et al (2005) Microsatellites reveal regional population differentiation and isolation in Lobaria pulmonaria an epiphytic lichen. Mol Ecol 14:457-467

Werth S, Sork VL (2008) Population biology, local genetic structure in a North American epiphytic lichen, Ramalina menziesii (Ramalinaceae). Am J Bot 95:568-576

Werth S, Wagner HH, Holderegger R et al (2006a) Effect of disturbances on the genetic diversity of an oldforest associated lichen. Mol Ecol 15:911-921

Werth S, Wagner HH, Gugerli F, Holderegger R (2006b) Quantifying dispersal and establishment limitation in a population of an epiphytic lichen. Ecology 87:2037-2046

Werth S, Gugerli F, Holderegger R (2007) Landscape-level gene flow in Lobaria pulmonaria, an epiphytic lichen. Mol Ecol 16:2807-2815

Williams NSG, Morgan J, McCarthy MA, McDonell MJ (2006) Local extinction of grassland plants: the landscape matrix is more important than patch attributes. Ecology 87:3000-3006

Wilson PJ, Provan J (2003) Effect of habitat fragmentation on levels and patterns of genetic diversity in natural populations of the peat moss Polytrichum commune. Proc R Soc Lond B 270:881-886

Wyatt R, Odrzykoski IJ, Cronberg N (2005) High levels of genetic variation in the haploid leafy liverwort Porella platyphylla. J Bryol 27:247-252 
Young AG, Boyle T, Brown T (1996) The population genetic consequences of habitat fragmentation for plants. Trends Ecol Evol 11:413-418

Zartman CE, McDaniel SF, Shaw AJ (2006) Experimental habitat fragmentation increases linkage disequilibrium but does not affect genetic diversity or population structure in the Amazonian liverwort Radula flaccida. Mol Ecol 15:305-2315

Zoller S, Lutzoni F, Scheidegger C (1999) Genetic variation within and among populations of the threatened lichen Lobaria pulmonaria in Switzerland and implications for its conservation. Mol Ecol 8:2049-2059 